\title{
Oro-genital ulcers with a positive pathergy test in acute myeloid leukaemia
}

\author{
B L P P Balasooriya ${ }^{1}$, H F S Fonseka ${ }^{2}$, S Williams ${ }^{3}$ and A Premawardhena ${ }^{1}$ \\ (Index words: leukaemia, genital ulcer, Behcet's disease)
}

\section{Introduction}

We report a young girl who presented with painful oral and genital ulcers and a positive pathergy test as a result of acute myeloid leukaemia M4 subtype. This is the first case report of this combination of signs and symptoms reported in acute myeloid leukaemia (AML).

\section{Case report}

An 18-year old unmarried girl presented with intermittent high grade fever and painful oro-genital ulcers of one month duration. Her past medical history, sexual history and family history were unremarkable. Clinically she was ill with tender mucosal ulcers in the mouth as well as in the genitals. There was no lymphadenopathy, hepatosplenomegaly or a skin rash. Her eyes were normal. One week later, she developed an asymmetrical, large joint arthritis involving the knees and ankles and painful tender red nodules over the shins, suggestive of erythema nodosum. Within 48 hours of insertion of intravenous cannulae as well as following venepuncture, pustular vesicles appeared at puncture sites (a positive pathergy test). A clinical diagnosis of Behçet's disease was made.

Her ESR was $110 \mathrm{~mm} /$ first hour and C-reactive protein was $190 \mathrm{mg} / \mathrm{l}$. The blood and urine cultures were sterile. Chest $\mathrm{x}$-ray and abdominal ultrasonography were normal. VDRL was non reactive. Anti nuclear antibody, HIV screening and herpes simplex antibody tests were negative.

The haemoglobin level was $9.1 \mathrm{~g} / \mathrm{dl}$ and white cell count was $11.7 \times 10^{6} / \mu 1$. The blood picture showed dysplastic neutrophils with pseudo pelger nuclei and 13\% blast cells (Figure 1). The bone marrow biopsy suggested a diagnosis of AML (M-4). The biopsy of mouth ulcers showed leukaemic deposits.

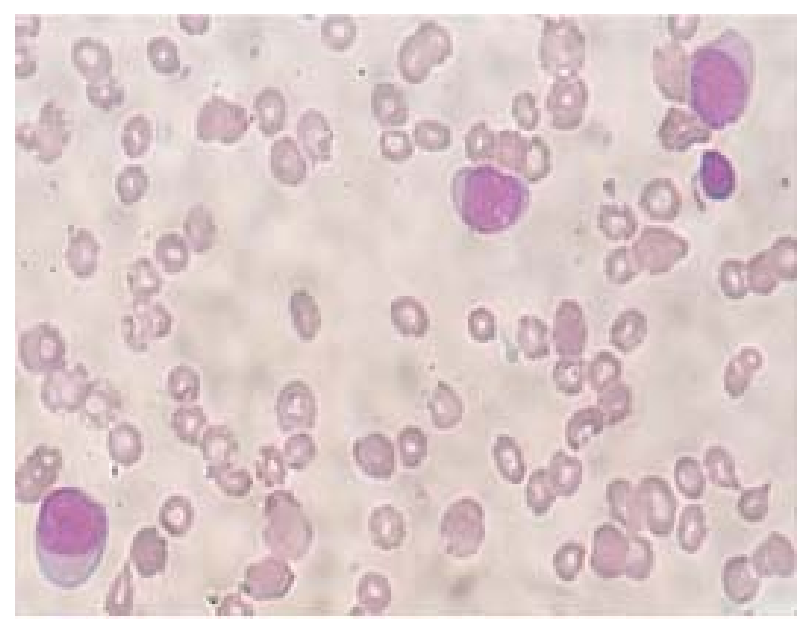

Figure 1. Blast cells with high nuclearcytoplasmic ratio.

Departments of ${ }^{1}$ Medicine and ${ }^{3}$ Pathology, Faculty of Medicine, Ragama and ${ }^{2}$ Dermatology Unit, Teaching Hospital, Ragama, Sri Lanka.

Correspondence: AP, e-mail <premawa@hotmail.com>. Received 14 May and revised version accepted 8 August 2009. Competing interests: none declared. 


\section{Discussion}

The main differential diagnoses of a patient with painful oral and genital ulcers include herpes simplex infection, Behcet's disease, HIV infection, connective tissue diseases, inflammatory bowel diseases and syphilis $[1,2]$.

A positive pathergy test is one of the diagnostic criteria for Behcet's disease [3]. With the presence of oral and genital ulcers, erythema nodosum and a positive pathergy test our patient fulfilled criteria for the diagnosis of Behcet's disease. However, a positive pathergy test rarely occurs in malignant disorders such as hairy cell leukaemia, T cell non-Hodgkin's lymphoma and chronic myeloid leukaemia treated with interferon alpha $[4,5,6]$. No previous reports suggest an association of a positive pathergy test with acute myeloid leukaemia.

Gingival hyperplasia in FAB M-4 acute myeloid leukaemia is well known. Though the occurrence of oral ulcers has been reported, a literature survey showed only two cases of genital ulcers in association with AML [7]. There are no previously reported cases of oral and genital ulcers together with a positive pathergy, mimicking Behcet's disease reported in the past. This case report highlights a rare presentation of acute myeloid leukaemia mimicking Behcet's disease with oro-genital ulcers and a positive pathergy reaction.

\section{References}

1. Gul A, Esin S, Dilsen N, et al. Immunohistology of skin pathergy reaction in Behçet's disease. British Journal of Dermatology 1995; 132: 901-7.

2. Dwarakanath AD, Yu LG, Brookes C, Pryce D, Rhodes JM. Sticky neutrophils, pathergic arthritis, and response to heparin in pyoderma gangrenosum complicating ulcerative colitis. Gut 1995; 37: 585-8.

3. Study Group for Behçet's Disease. Criteria for diagnosis of Behçet's disease. Lancet 1990; 335: 1078-80.

4. Kaplan RP, Newman G, Saperia D. Pyoderma gangrenosum and hairy cell leukaemia. Journal of Dermatology Surgery Oncology 1987; 13: 1029-31.

5. Djawari D, Hornstein OP, Luckner L. Skin window examination according to Rebuck and cutaneous pathergy tests in patients with Behçet's disease. Dermatologica 1985; 170: $265-70$.

6. Budak-Alpdogan T, Demircay, Alpdogan O. Skin hyperreactivity of Behçet's patients (Pathergy reaction) is also positive in interferon alpha-treated chronic myeloid leukaemia patients indicating similarly altered neutrophil function in both disorders. British Journal of Rheumatology 1998; 37: 1148-51.

7. Guptha A, Maheshwari A, Gujral S, et al. Acute leukaemia presenting as vulvar ulcers in an adolescent girl. The Australian and New Zealand Journal of Obstetrics and Gynaecology 2005; 45: 536-7. 